\title{
Recent Developments in Weinreb Synthesis and Their Applications (A-Review)
}

\author{
MAHER KHALID*, SHIREEN MOHAMMED and AMIN KALO \\ Department of Chemistry, Faculty of Science, Zakho University, Duhok Street, \\ 42002 Kurdistan - Region, Iraq. \\ ${ }^{*}$ Corresponding author E-mail: maher-333@ hotmail.de \\ http://dx.doi.org/10.13005/ojc/350601
}

(Received: November 11, 2019; Accepted: December 12, 2019)

\begin{abstract}
$\mathrm{N}$-methoxy- $\mathrm{N}$-methyl amides or Weinreb amides are worthy embranchment of amide group and their rich functional groups in organic synthesis become a strong else unfeasible conversion. Weinreb amides are produced as an intermediate product of the reaction of carboxylic acids, acid chloride or esters with organometallic reagents, which was first uncovered in 1981. The direct conversion of carboxylic acids or acid chlorides or esters to ketones or aldehydes using organometallic reagents do not lead in high yields, because the intermediate ketones are still highly reactive toward the organometallic reagent. However, after derivatization to the corresponding Weinreb amide, reaction with organometallics does give the desired ketones, as the initial adduct is stabilized and doesn't undergo further reactions. A nucleophilic addition to the Weinreb amides results in a unique and stable five-membered cyclic tetrahedral intermediate which protects the over-addition, leading to a selective conversion.
\end{abstract}

Keywords: $N$-Methoxy- $N$-methyl amide, Weinreb amide, Acylating agents, Asymmetric hydrogenation, Palladium-catalyst, $\mathrm{C}-\mathrm{H}$ functionalization, Organometallic reagents.

\section{INTRODUCTION}

$\mathrm{N}$-methoxy- $\mathrm{N}$-methylamides or Weinreb amides become a worthy synthetic precursor in organic synthesis. ${ }^{1}$ The first synthesis of Weinreb moiety was reported in 19812 . This reaction called Weinreb amidation, included preparation of $\mathrm{N}$-methoxyl-N-methyl amides from $\mathrm{N}$, O-dimethyl hydroxylamine using $\mathrm{AlMe}_{3}$ as a coupling reagent. Thereafter, diverse access for the synthesis of Weinreb amides has been announced, such as direct transformation of carboxyl group into the equivalent ketone or aldehyde. Remarkably, the efficiency of Weinreb intermediate to submit a single substitution reaction with excess organometallic reagents is essential to its publicity as acylating agents $^{3}$ in the laboratory and industrial synthesis processes. Weinreb intermediate could neatly react with organolithium ${ }^{4}$, Grignard reagents ${ }^{5}$, and $\mathrm{LiAlH}_{4}{ }^{6}$ to produce aldehydes or ketones newly; it could react with Wittig reagents to yield ketones ${ }^{7}$. Nowadays, much effort has been dedicatedto the way to develop their soft and Universal synthesis. Such, Weinreb amides can be synthesized from carboxylic acids ${ }^{8}$, acid chlorides ${ }^{9}$, amides ${ }^{10}$, esters ${ }^{11}$, lactones ${ }^{12}$, and anhydrides ${ }^{13}$. Furthermore, the easy transformation of carboxylic acids to the Weinreb amides is much more attractive.

This is an Open Access article licensed under a Creative Commons license: Attribution 4.0 International (CC- BY). Published by Oriental Scientific Publishing Company @ 2018 
Due to the fast development of Weinreb amides synthesis and their applicationsin the last ten years, it was motivating to review whole the recently published papers in the period from 2010 up to 2019 and details some neoteric developments of these strategy processes.

In 2010, Jang and co-workers ${ }^{14}$ describeda flexible one-pot process for the synthesis of Weinreb amides from carboxylic acids using trichloroacetonitrile (TCA) and triphenylphosphine (TPP) (Scheme 1). Here, the authors presumed that carboxylic acid chlorides generated in situthrougha combination of carboxylic acids 1 with TCA and TPP, followed by treatment with $\mathrm{N}, \mathrm{O}$-dimethylhydroxylamine in the presence of triethylamine (TEA) to produce the corresponding Weinreb amides. The feature of such reaction is that it can perform satisfactorily with various aliphatic and aromatic carboxylic acids, which showed asoft level to produce the desired products 2 with high yields $(75-93 \%)$.

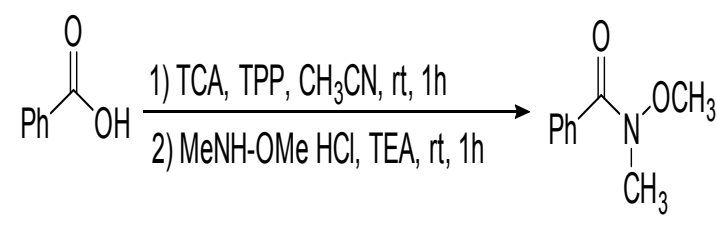

Scheme 1. Synthesis of N-Methoxy-N-methyl amides from carboxylic acids

In parallel, Davis and Theddu ${ }^{15}$ reported a new methodology forthe asymmetric synthesis of cyclic $\beta$-amino acid derivatives ${ }^{6}$ viafive-, six-, and sevenring-closing metathesis of sulfiniminederived $\mathrm{N}$-sulfinyl $\beta$-amino diene Weinreb amides (Scheme 2). The protocol here described introducing $\mathrm{N}$-sulfinyl $\beta$-amino Weinreb amides ${ }^{5}$, which furnished aninclusive solution to overcome the problem of enantiopure $\beta$-amino ketone and aldehyde synthesis. However, the addition of Weinreb amide enolates ${ }^{4}$ to sulfinimines ( $\mathrm{N}$-sulfinyl imines) ${ }^{3}$ was used for the first time to prepare $\mathrm{N}$-sulfinyl $\beta$-amino Weinreb amides.<smiles>COC(=O)Cc1ccccc1</smiles>

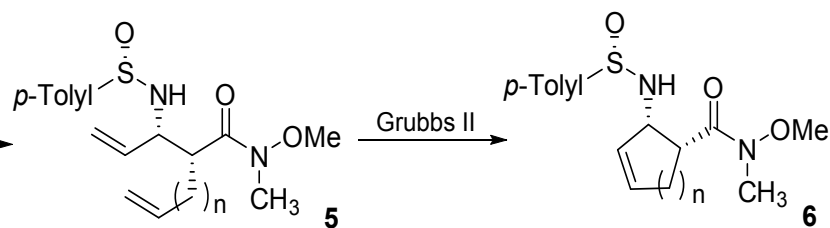

Scheme 2. Asymmetric synthesis of cyclic cis- $\beta$-Amino acid derivatives

Furthermore, Aidhenand co-workers ${ }^{16}$ detailed facile synthesis of $N$-methoxy- $N$-methyl$\mathrm{N}$-phenylsulfonyl glycinamide and $\mathrm{N}$-methoxy$N$-methyl- $N$-benzyl- $N$-tert-butyloxy carbonyl glycinamide equivalents using Weinreb amide functionality, which considered a valuable route for the universal synthesis of 4-aryl- 1,2,3,4-tetrahydroisoquinoline derivatives (Scheme 3). Uncommonly, the two normal reactions, $\mathrm{N}$-benzylation and addition of aryl magnesium halide $^{8}$ on the Weinreb amide ${ }^{7}$, deigned thekey intermediate $^{9}$ for suitable synthesis of 4 -aryl1,2,3,4-tetrahydroisoquinolines ${ }^{11}$ in high yields $(97-99 \%)$.

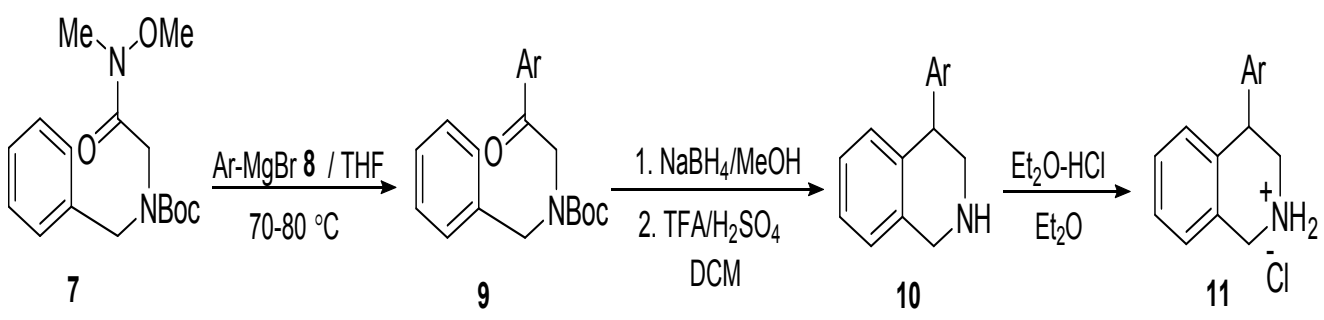

Scheme 3. Synthetic equivalents for convenient access to 4-aryl-1,2,3,4-tetrahydroisoquinolines

Furthermore, Herr and co-workers ${ }^{17}$ detailed the efficient role of palladium-catalyst in preparation of benzamides ${ }^{16}$ and $\alpha, \beta$-unsaturated
Weinreb amides ${ }^{15}$ using organoboronic acids (12 or 13) and $\mathrm{N}$-methyl- $\mathrm{N}$-methoxy carbamoyl chloride substrate ${ }^{14}$ (Scheme 4$)$. Under optimization 
conditions, using potassium phosphate monohydrate as a base and dry ethanol as a solvent at $65^{\circ} \mathrm{C}$, the key incorporation between the substrates with the palladium catalyst, confirmed one-pot synthesis of the expected products. Variety of aromatic organoboronic acids bearing electron-withdrawing and electron-donating groups, displayed a wide manner toward the reaction conditions.

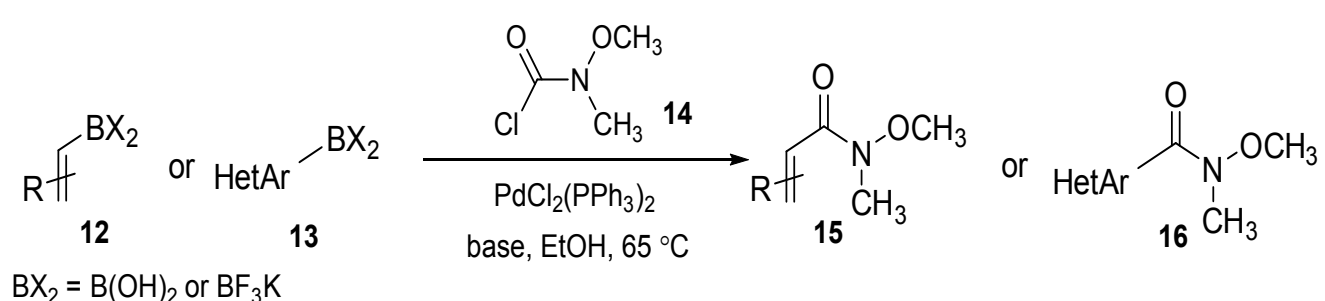

$\mathrm{BX}_{2}=\mathrm{B}(\mathrm{OH})_{2}$ or $\mathrm{BF}_{3} \mathrm{~K}$

Scheme 4. Palladium-Catalyzed preparation of Weinreb amides from boronic acids and $\mathrm{N}$-Methyl-N-methoxycarbamoyl chloride

Furthermore, Lakshman and co-workers ${ }^{18}$ illustrated an effective transformation of carboxylic acids to the corresponding secondary, tertiary, and Weinreb amidesusingPPh $\mathrm{I}_{2}$ or $\mathrm{Pol}-\mathrm{PPh}_{3} / \mathrm{I}_{2}$ (Scheme 5). The mechanism the strategy firstly, proceeds through combination between $\mathrm{PPh}_{3}$ and $\mathrm{I}_{2}$ in a $1: 1$ ratio, produced a newspecies represented by $\left(\mathrm{Ph}_{3} \mathrm{P}^{+-}-1\right) I^{-}$. The latterqualified to react with carboxylic acids ${ }^{17}$ in presence of $\operatorname{Pr}_{2} \mathrm{NEt}$ and form either an acyl phosphonium species17ior an acyl iodide17ii. The reaction of the resultants with the amine ${ }^{18}$, produce the final amide products ${ }^{19}$.

In 2011, Odell and co-worker ${ }^{19}$ represented a direct methodology for the synthesis of Weinreb and MAP aryl amides via Heck amino carbonylation under microwave irradiation process (Scheme 6). The protocol of such reactions proceed through treatment of hetero-aryl bromides and iodides20 with (21 or 22), $\mathrm{Pd}(\mathrm{OAc})_{2}$ catalyst, Xantphos ligand,
$\mathrm{W}(\mathrm{CO})_{6}$ or $\mathrm{Mo}(\mathrm{CO})_{6}$ as the $\mathrm{CO}$ source and $\mathrm{K}_{3} \mathrm{PO}_{4}$ base in dioxane solvent for $30 \mathrm{~min}$ under the microwave irradiation. Different functional groups were tolerated and the expected products ( 23 and 24) were obtained in good yields. The achievements of these protocols are quite determined and insuretheir low cost, short time, andthe generation of toxic CO-gas In situ.

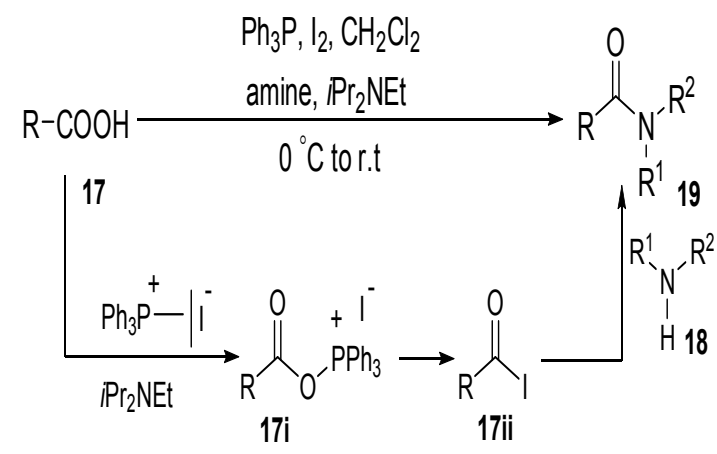

Scheme 5. Synthesis of amides and Weinreb amindes Using $\mathrm{PPh}_{3}$ or Polymer-Supported $\mathrm{PPh}_{3}$ and lodine

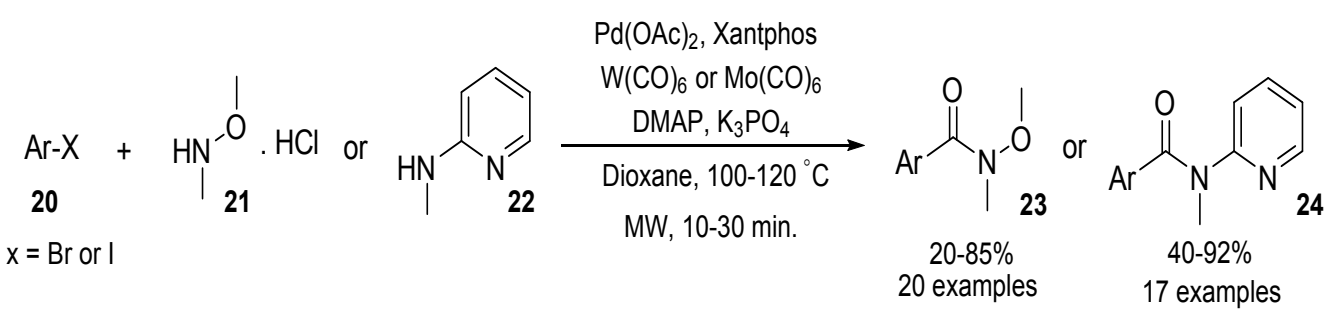

Scheme 6. Synthesis of Weinreb and MAP aryl amides via Pd-Catalyzed heck aminocarbonylation using $\mathrm{Mo}(\mathrm{CO})_{6}$ or $\mathrm{W}(\mathrm{CO})_{6}$

Later, Aidhen and co-worker ${ }^{20}$ drew a novel strategy for the synthesis of equivalent, including Weinreb amide as a backbone for general synthesis of 1,1-diarylethenes and particularly synthesis of iso combretastatin 30 starting from glyoxalic acid substrate 25 (Scheme 7). The appropriateness which thestructural diversity can be made in combing the aryl remains provided most related 
to the improvement protocol. Furthermore, the intermediates (26-29) supplied oncoming to 1,2,2- triarylethanones, performed bythe synthesis of progressive intermediate of tamoxifen.

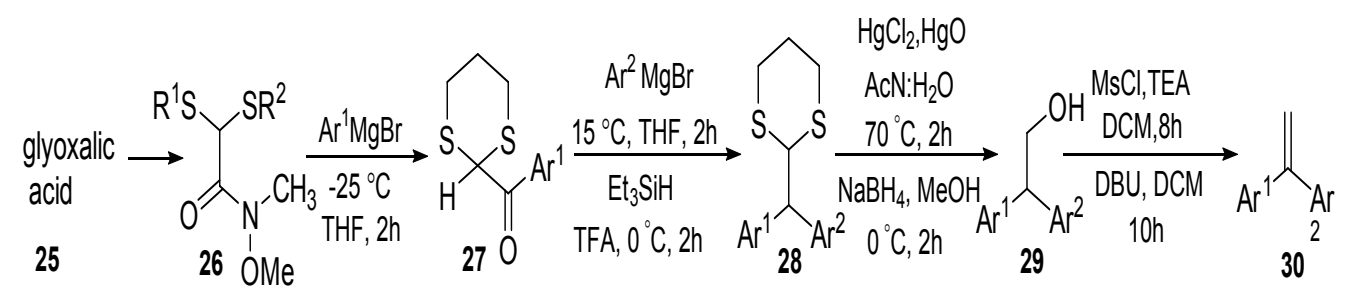

Scheme 7. Weinreb amide based building blocks for convenient access to 1,1-diarylethenes and isocombretastatin analogues

Meanwhile, Pelkey and co-worker ${ }^{21}$ reported a new protocol for the synthesis of symmetrical and unsymmetrical 3,4-Diaryl-3pyrrolin-2-ones (Scheme 8). This synthesis proceeds steadily via reactions between $\beta$-nitrostyrenes and pyrrole-2-carboxamides (pyrrole Weinreb amides)utilizing as the key intermediates. The authors suggested two reaction pathways for preparation of nitroalkenes: Firstly, Henry reaction modification between arylnitromethanes33 and arylimines34 (method $\neq 1$ ), and secondly, Suzuki-
Miyauracross-coupling reaction of 2-aryl-1-bromo-1nitroethenes 36 with aryl boronic acids (method $\neq 2$ ). Furthermore, Barton-Zardpyrrole cyclo condensation process between 1,2-diaryl-1-nitroethenes35 and $\mathrm{N}$-methoxy-N-methyl-2-isocyanoacetamide38, afforded synthesis of pyrrole Weinreb amides39, followed by transformation to the corresponding 3,4-diaryl-3-pyrrolin-2-one compounds 41over two steps. One of the applications of such reaction was preparation eight 3,4-diaryl-3-pyrrolin-2-ones containing the $\mathrm{N}-\mathrm{H}$ lactam peer of rofecoxib.

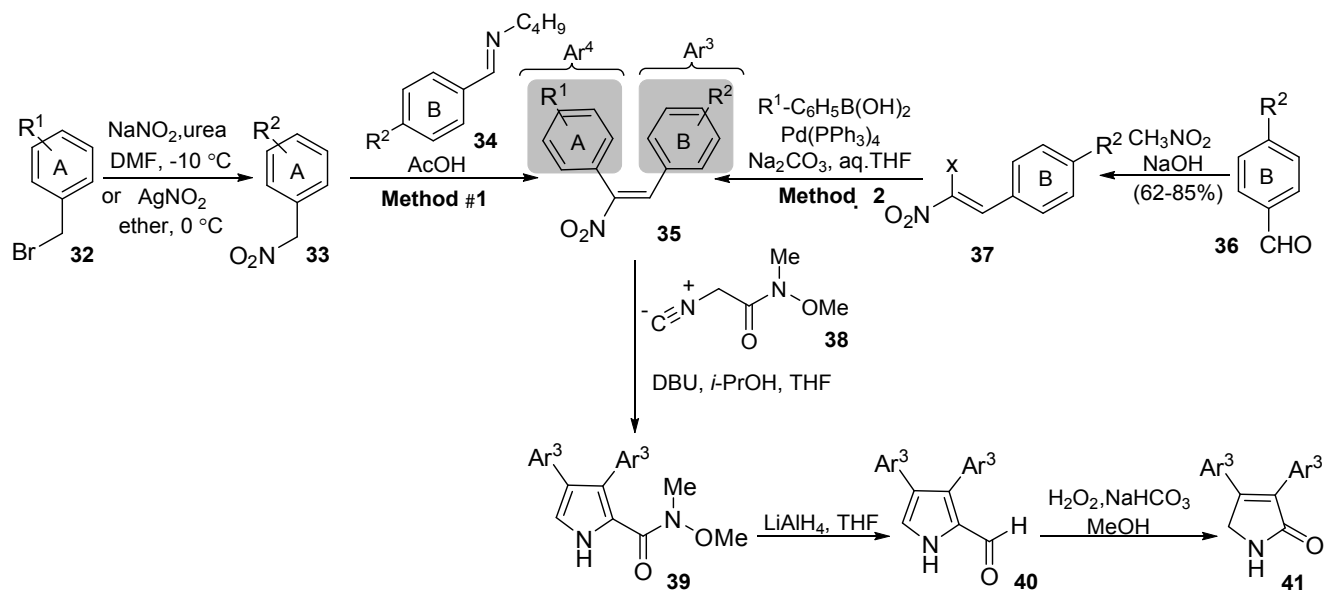

Scheme 8. Synthesis of Unsymmetrical 3,4-Diaryl-3-pyrrolin-2-ones utilizing pyrrole Weinreb amides

While Tyrrell and co- worker ${ }^{22}$ detailed the efficient transformation of $\alpha$-amino acids to Weinreb amides using(COMU) asa coupling agent (Scheme 9). Generally, a mixture of $\mathrm{N}$-protected $\alpha$-amino acids 42 and $\mathrm{N}$-methoxy-N-methylamine hydrochloride43 in presence of COMU, and DIEA in DMF at $0^{\circ} \mathrm{C}$, afforded Weinreb amide products44 in high yields $(63-97 \%)$. Because the by-products of the reaction are handilywater-soluble, the products are separated comparatively pure and with lower racemization.

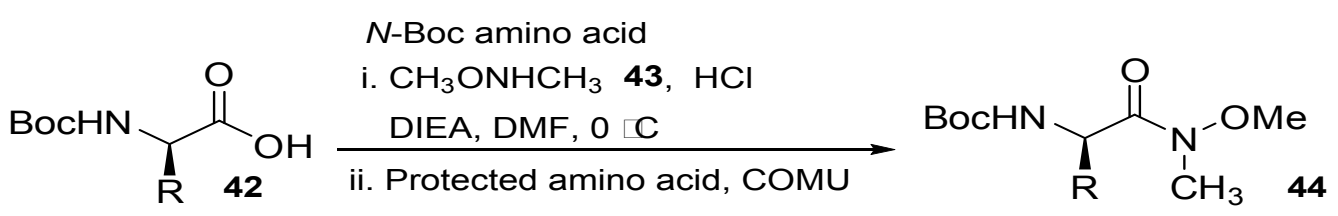

Scheme 9. Onversion of a-amino acids into Weinreb amides using COMU as a coupling agent 
Independently, Guogroup ${ }^{23}$ has detailed the importance role of $[R u((S)$-Sunphos)(benzene) $\mathrm{Cl}] \mathrm{Cl}$ as the catalyst and $\mathrm{CeCl}_{3} \cdot 7 \mathrm{H}_{2} \mathrm{O}$ as the additive in the asymmetric hydrogenation of $\alpha$-keto Weinreb amides(Scheme 10). Normally, the ratio of $\mathrm{CeCl}_{3} \cdot 7 \mathrm{H}_{2} \mathrm{O}$ to $[\mathrm{Ru}((\mathrm{S})$-Sunphos)(benzene) $\mathrm{Cl}] \mathrm{Cl}$ displayed the significant function in the hydrogenation reaction. It is remarkable that different functional groups in $\alpha$-keto Weinreb amides 45 were screened and resulted an obvious scope toward the reaction conditions, giving the desired $\alpha$-hydroxy Weinreb amide products (46 and 47 ) in high yields (up to $97 \%$ ee).

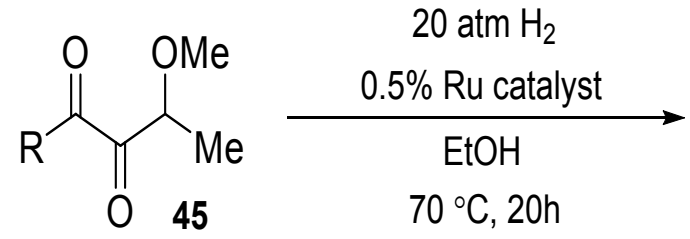<smiles>[R]C(O)C(=O)N(C)C</smiles><smiles>[R]C(O)C(=O)NC</smiles>

Scheme 10. Ru-catalyzed highly enantioselective hydrogenation of a-keto Weinreb amides

In 2013, a straightforward access to the synthesis of benzimidazoles and benzothiazoles 50 in one pot was described by Rangappa group ${ }^{24}$ (Scheme 11).This reaction proposed to proceed clearlyvia a condensation reaction between Weinreb amide 49 and (o-diaminoarene or o-aminothiophenol) 48, followed by cyclization process in present of boron trifluoride etherate in dioxane solvent at $100^{\circ} \mathrm{C}$ for 60 minutes. This optimal condition displayed the efficient role of Weinreb amide substrate49 toward the cyclization process, even in presence of other energetic functional groups like methoxy, carboxyl, cyano and halogen. However, using one pot synthesis shows the Weinreb amide high selectivity in the reaction.<smiles>[R]c1ccc([Y])c(N)c1</smiles>

$X=N H, S$

$\mathrm{R}^{1}=\mathrm{H}, \mathrm{CH}_{3}, \mathrm{Br}$

$\mathrm{R}=$ alkyl, Akenyl, Aryl, Heteroaryl

Scheme 11. One pot synthesis of benzimidazoles and benzothiazoles using Weinreb aminde as an efficient reagent

Later, Pace and co-workers ${ }^{25}$ announced a new novel protocol for the synthesis of Weinreb amidesbeginning from readily available obtainable acid halides51 using N,O-dimethylhydroxylamine hydrochloride (DMHA)52 in the biphasic medium 2-MeTHF/ $\mathrm{H}_{2} \mathrm{O}$ (Scheme 12).Virtually, this method afforded pure products53 with excellent yields after simply remove of 2-MeTHF and no need to further organic solvents in the purification step. Moreover, the different substituents on the acid halide framework, containing electron withdrawing group and electrondonating group, were tolerated and revealedhighly effective substrates, leading to the pure products 53 .

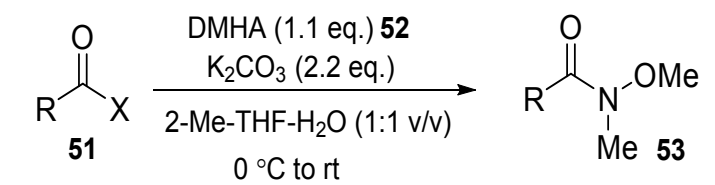

$\mathrm{X}=\mathrm{Br}, \mathrm{Cl}$

Scheme 12. Preparation of Weinreb amindes in the biphasic system 2-MeTHF/water

Later, functionalization of Weinreb amides to the corresponding asymmetric aldehydes and ketones containing chiral centers have been developed by Davies group ${ }^{26}$ (Scheme 13). The authors suggested two synthetic routes to get the corresponding enantio pure aldehydes or ketones: Firstly, preparation of amide followed by hydride reduction or the addition reaction with organometallic reagent. Secondly, preparation of alcohol via reductive cleavage of the chiral auxiliary, followed then by re-oxidation reaction to produce the corresponding aldehyde. Actually, using chiral auxiliaries such as $\mathrm{N}$-acyl derivativesqualified for functioning as potentialaldehyde and ketone products 57 and 58 through immediately cleavage of the auxiliary. 


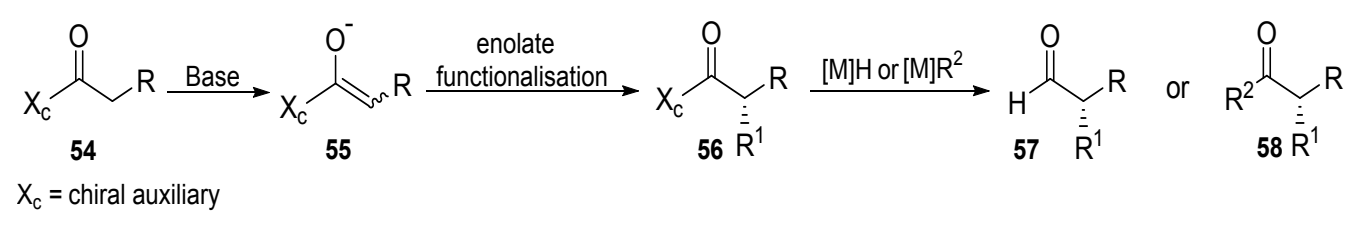

Scheme 13. Asymmetric syntheses of chiral aldehydes and ketones via chiral auxiliary approaches including chiral Weinreb amide equivalents

In parallel anovel procedure for synthesis of $\mathrm{N}$-protected $\alpha$-amino/peptide Weinreb amides were described by Sureshbabu group ${ }^{27}$ (Scheme 16). The protocol here depended on the reaction range of $\mathrm{Fmoc}$, Boc or $\mathrm{Cbz}$-protected amino acids 59 with $\mathrm{N}, \mathrm{O}$-dimethylhydroxylamine substrate in presence of T3P and DBUin $\mathrm{CH}_{3} \mathrm{CN}$ at $0^{\circ} \mathrm{C}$ for 30 minute. The key combination between T3P and DBU, afforded superior result and encouraged synthesis of the corresponding Weinreb amide products60. Furthermore,the molecular structure of Weinreb amide was characterized through X-ray crystallography.

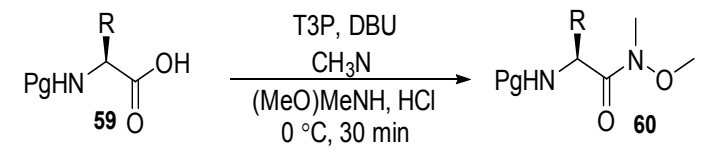

$\mathrm{Pg}=\mathrm{Fmoc}$, Boc or $\mathrm{Cbz}$ group

$\mathrm{R}=$ amino acids side chain

Scheme 14. Synthesis of $\mathbf{N}^{\alpha}$-protected amino/peptide Weinreb amides from T3P and DBU

In 2014, Bhanage and co-workers detailed the effective role of $\mathrm{Pd}(\mathrm{OAc})_{2} / \mathrm{DABCO}$ as catalyst under phosphine-free conditions in the synthesis of single and double Weinrebamides ${ }^{28}$ (Scheme 15).This process proceeds steadily through one-pot aminocarbonylationofaryl iodides61, $\mathrm{Pd}(\mathrm{OAc})_{2}, \mathrm{DABCO}, \mathrm{Na}_{2} \mathrm{CO}_{3}$, in $\mathrm{CH}_{3} \mathrm{CNunder}$ an atmospheric pressureof carbon monoxide, to produce the corresponding products with excellent yields (83-95\%).A reasonable mechanistic for this reaction forwardsviaThree main steps includes, oxidative addition with palladium (0), migratory insertionof $\mathrm{CO}$, and finally, nucleophilic reaction with the $\mathrm{N}$-methoxy- $\mathrm{N}$-methyl amine moiety62 to transform to the corresponding Weinerb amide product63. No need to expensive and sensitive phosphine ligands and stability of $\mathrm{DABCO}$ ligand for the $\mathrm{Pd}(\mathrm{OAc})_{2}$, were the best advantages for such protocol.

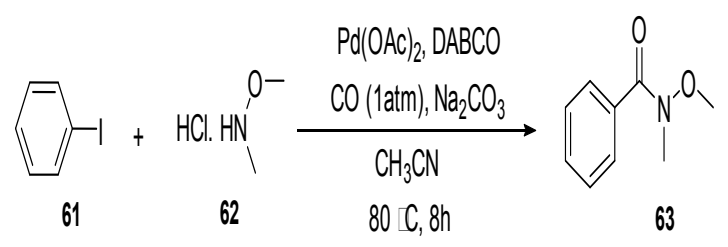

Scheme 15. Synthesis of Weinreb amides by the aminocarbonylation of aryl iodides using $\mathrm{Pd}(\mathrm{OAc})_{2} / \mathrm{DABCO}$

Next, Rahaim and co-workers ${ }^{29}$ revealed a modest application of titanium catalyst mediated there gioselective synthesis of Enones(Scheme 16). Normally, the reaction approved by the coupling reaction between unsymmetrical internal alkynes 64 with Weinreb amides65, giving the trisubstituted enone products 66 in reasonable chemoselectivityto good yields. It is noticeable that range of functional groups in Weinreb amides, function a wide amplitude toward the reaction conditions producing the relating products in moderate to excellent yields (51-95\%).

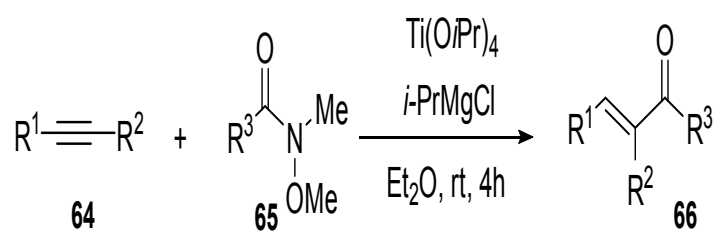

Scheme 16. Synthesis of Enones via a Titanium promoted coupling of unsymmetrical alkynes with Weinreb amides

On the other side, Seayadand co-workers ${ }^{30}$ incorporate version, high yielding and help ful procedure for synthesis of Weinreb amides and ketones starting from aryl bromide or iodide substrates (Scheme 16). The protocol here, focused on the coupling reactions of aryl iodides or bromides 67 with N,O-dimethylhy droxyaminehydrochloride69 in the presence of $\mathrm{Pd}$ nanoparticles supported on ZIF-8 under comparatively direct aminocarbonylation conditions processes. This method displayed the efficient role of palladium catalyst in the synthesis of diverse functionalized Weinreb amides 70 with perfect yields (75-98\%). It is noteworthy that the catalyst $\mathrm{Pd} / \mathrm{ZIF}-8$ could be recovered and scale up potential was alsoproved in a gram scale achieving a 1000 of about 1500 . 


$$
\begin{array}{ll}
\mathrm{X}=\mathrm{Br} \\
67
\end{array}
$$

Scheme 17. Synthesis of Weinreb amides and ketones via palladium nanoparticles on ZIF-8 catalysed carbonylative coupling

On the other side, the synthetic and mechanistic studies of reductive of $\mathrm{N}-\mathrm{O}$ bond cleavage of Weinreb amides promoted by sodium in aluminaand silica gels(Na-AG) and (Na-SG) has been studied by Jackson group ${ }^{31}$ (Scheme 18).Generally, the clarity of such reactions, turn on under optimal conditions, is analogous with the protocols used for similar reactions using reagent such as Sml2/THF at $\left(-78^{\circ} \mathrm{C}\right)$, or Li/di-t-Butylbiphenyl at $\left(-78^{\circ} \mathrm{C}\right)$. In this work, various functional groups of Weinreb amides71 were tested, demonstrated their obviously novel group transfer feature, implicationbase-utilized cleavage of the Weinreb amide to produce formaldehyde, followed by aldol condensation reaction. Furthermore, high reduction selectivity with simple Weinreb amide substrates was observed.<smiles>CNC(=O)c1ccccc1</smiles>

Scheme 18. Reductive N-O cleavage of Weinreb amides by sodium in alumina and silica gels

In parallel, Wang and co-workers ${ }^{32}$ detailed the first uses of palladium catalyst in the directed $\mathrm{C}-\mathrm{H}$ functionalization of Weinreb amides (Scheme 19). Normally, the reaction between either aryl Weinreb amides or benzyl amides 74 and iodoarenes 75 in the presence of palladium acetate as the pre-catalyst in DCE solvent, encouraged transformation of expected final products76. A range of Weinreb amides containing bothelectron- withdrawing and -donating groups as well as halogen were exposedto the reaction conditions and demonstrated highly efficient substrates, leading to the desired products.

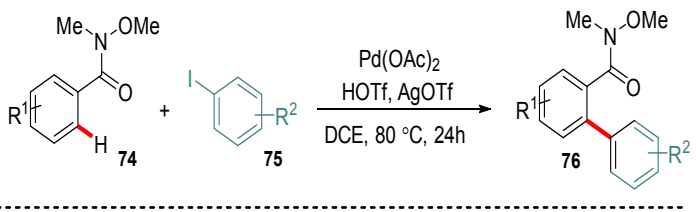

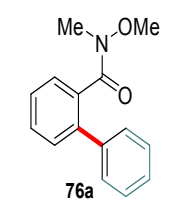
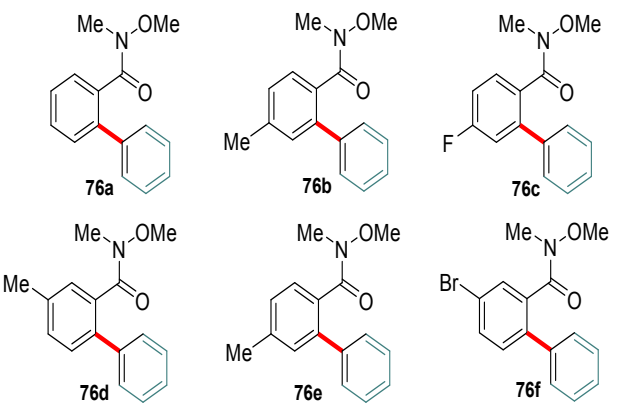

Scheme 19. Pd-catalyzed C-H arylation of aryl and benzyl amides

Moreover, Yamamoto and co-workers ${ }^{33}$ described the novel usage of $\operatorname{Ir}(\mathrm{III})$ catalyst in the asymmetric intermolecular hydroarylation of arenes oriented by oxygen setup group (Scheme 20). Actually, this scope detailed an exclusive example of Weinreb Amide product79 employing the bidentatebis (phosphoramidite) ligand.
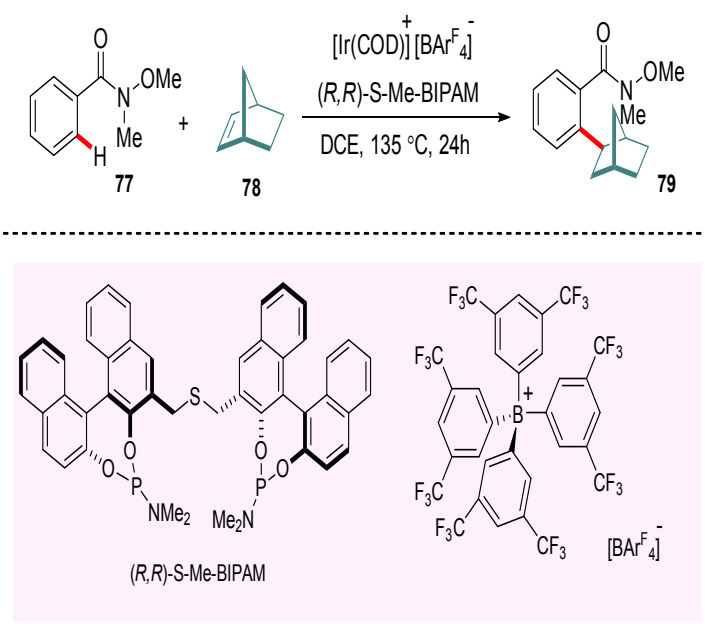

Scheme 20. Ir-catalyzed enantioselective C-H hydroarylation of an olefin, directed by a Weinreb amide

Compared to the rapid development in the scope of $\mathrm{C}-\mathrm{H}$ Functionalization process, Das and Kapur ${ }^{34}$ have used ruthenium as a rapid catalystin Fujiwara-Moritanior the oxidative-Heck reaction of Weinreb Amides (Scheme 21).This reaction mechanism suggested to forward simply through three main steps includes, coordination of carbonyl oxygen Weinreb amide substrate80 with Rull, followed by $\mathrm{C}-\mathrm{H}$ activation through carbometallation 
step and finally, $\beta$-hydride elimination and affording products 82 with moderate to excellent yields (54-95\%).Overall,awide variety of beneficial of activated olefins81 as well as styrenes istolerated under the mild conditions, capable a softcoupling partners.

$$
\text { }
$$

Scheme 21. Fujiwara-Moritani Reaction of Weinreb amides using a Ruthenium-Catalyzed $\mathrm{C}-\mathrm{H}$ functionalization reaction

After one year, the same group published a paperutilizing the same Rull catalyst in synthesis of a newform of Weinreb amides via Heck or the oxidative-Heck reactions ${ }^{35}$ (Scheme 22). Here, the reaction mechanism preceded first through the complexion between amide carbonyl oxygen group83 and cationic ruthenium complex by the regioselective oxidative $\mathrm{C}-\mathrm{H}$ olefination. Generally, two diverse intermediates are probable, 5-membered ruthenacycle or 6-membered ruthena cycle.The high proportional stability of the 5 -membered ruthenacycle intermediate, allowed it to coordinate with the olefin84, followed by $\beta$-hydride elimination to form the final product85. Meanwhile, mechanistic studies disclosed pleasant parts of thedirecting group abilities of simple structure Weinreb amides.<smiles>[R]C=C=[18O]</smiles>

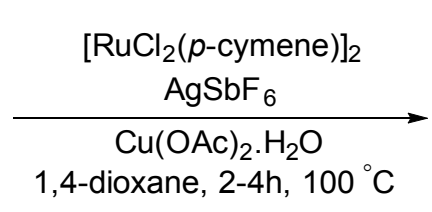<smiles>[R]C=Cc1c[R1]ccc1C(=O)N1CCCCCO1</smiles>

Scheme 22. Ruthenium-Catalysed oxidative C-H olefinations of cyclic Weinreb amides

Moreover, Wang and co-workers ${ }^{36}$ described a dynamic route for the synthesis of 2 -Ns-Protected $\beta$-amino Weinreb amides via amino chlorination of $\alpha, \beta$-unsaturated Weinreb amides in an ionic liquid, 1-n-butyl-3-methylimidazolium bis(trifluoromethanesulfonyl)imide ([BMIM][ $\left.\mathrm{NTf}_{2}\right]$ ) (Scheme 23). Generally, when this reaction transfers theionic liquid to [BMIM][NTf $]$, it was shown that the starting material $N$-methoxy- $N$-methyl cinnamoyl amide 86 was transformed absolutely after $24 \mathrm{~h}$ in the absence ofany metal catalysts. Additionally, under the optimal reaction conditions, the aminochlorination reactions using $2-\mathrm{NsCl}_{2} 87$, performed steadily, and the expecting $\alpha$-chloro- $\beta$-amino products were gain edinmoderate to good yields (40-83\%) and outstandin gregio selectivities. It is noteworthy to indicated that this method has some benefits like the isolation of the diastereomers products 88 and 89 is totally easy though flash column chromatography and the reaction conditions are compatible at room temperature without using metal catalysts or presence of an inert gases safeguard.

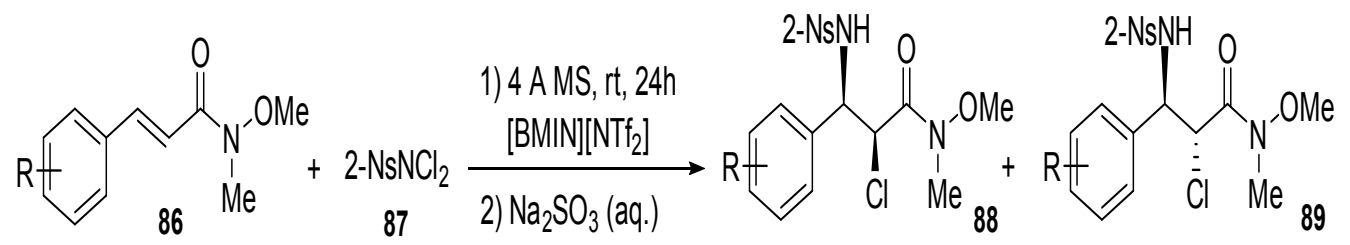

Scheme 23. $\beta$-Amino functionalization of cinnamic Weinreb amides in ionic liquid

Later, Collum and co-workers reported a soft and efficient synthesis of Weinreb enolates91 through coordination between Weinreb amides 90 and LDA base in dry THF/benzene mixture solvents ${ }^{37}$ (Scheme 24). Routinely, enolates form tetramers and dimers represented normally as 93 and 94, respectively. The generalityremarkable results of this method were produced that the experimental and computational data proposed, apparently straightforward function of mutual solvation by THF ligands and the chelating methoxy species. The coordination by lithiumbuild cubic tetramers 93 may gain remarkably coordination numbers for further implementations in synthesis 92 . 


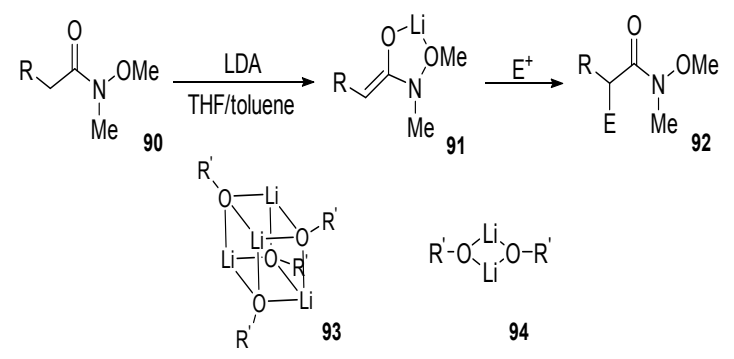

$\mathrm{R}^{\prime}=\mathrm{H}, \mathrm{CH}_{3}, \mathrm{CH}_{2} \mathrm{CH}=\mathrm{CH}_{2}, \mathrm{Bn}, \mathrm{Ph}, 2$-naphthyl, 2,5- $(\mathrm{MeO})_{2} \mathrm{C}_{6} \mathrm{H}_{3}$

Scheme 24. Lithium enolates derived from Weinreb amides: Insights into Five-Membered chelate rings

Rueping and co-workers ${ }^{38}$ promoted the oxidativeal kenylation of aromatic amides, involving Weinreb amides, in presence of $\left[\mathrm{Ru}(\mathrm{bpy})_{3}\right][\mathrm{PF} 6]_{2}$ as a catalyst (Scheme 25). The method is remarkable not just for its qualification and crucial effective group tolerance, but also actuality it can bewide spread to other amides and a diversity of olefin substrates. The mechanism of such reaction supposed to proceed through primarily with ortho-rhodation of Weinreb amide substrates95, coordination and insertion of the olefin96, followed by $\beta$-hydride elimination step to form the corresponding products 97 .
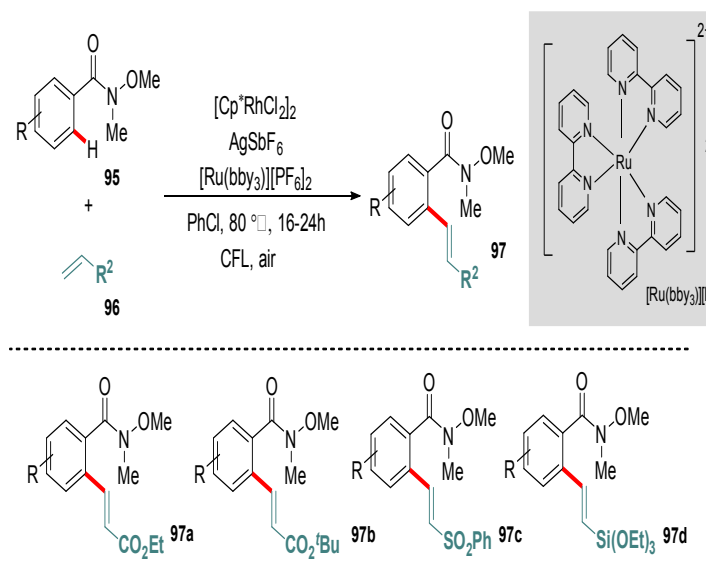

Scheme 25. Rh-catalyzed olefination of aromatic Weinreb amides enabled by Ru photocatalysis

Regarding to the unusual achievement of Weinreb amides asnotableacylating agents in the chemoselectiveomologation reactions with $\alpha$-substituted methyllithium reagents, Pace et al. ${ }^{39}$ reported a modern route for the isolation and demonstration of tetrahedral intermediates through addition of Lithium carbenoidsto Weinreb amides(Scheme 26). This method suggested to proceed viaaddition ofrobustly nucleophilic organometallic reagents, such as $\left(\mathrm{LiCH}_{2} \mathrm{X}\right.$ and
LiCHXY)99 to different substituent of Weinreb amideand $\mathrm{N}$-acyl pyrroles substrates 98 through Barbier-type conditions $98 \mathrm{i}$, followed by combination with Im-TMS 100 (as the trapping agent), then treatment with $\left(\mathrm{NaHCO}_{3}, 5 \%\right)$ and finally purification by Brockmann grade neutral alumina (AloxNBG3),switching to the corresponding O-trimethylsilyl protected hemiaminal products 101 .

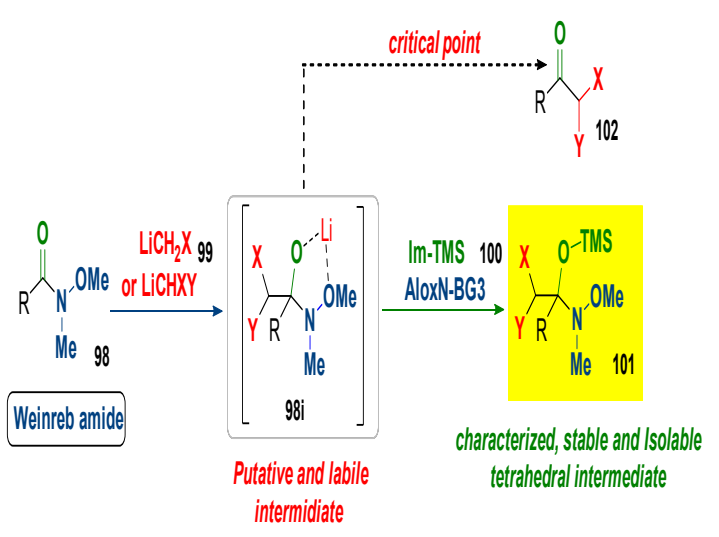

Scheme 26. Tetrahedral intermediates formed upon the addition of lithium carbenoids to Weinreb amides and $\mathrm{N}$-acylpyrroles

While Kapur et al., ${ }^{40}$ reporteda novel usage of palladium-catalyzedortho $\mathrm{C}-\mathrm{H}$ halogenation of aromatic substrates including soft-coordinating groups (Scheme 27). Under palladium catalyst cycle and in one-pot usingaprotic solvent, a convenient substrates 103 including critical functional groups such as benzoic acid Weinreb amides, anilides, and benzyl nitriles were tolerated and shown an excellent transformation to the corresponding products 104, 105 and 106 with higher regioselectivity. Moreover, mechanistic studies output delightful parts with regard to the route of the reaction and the directing group efficiency.

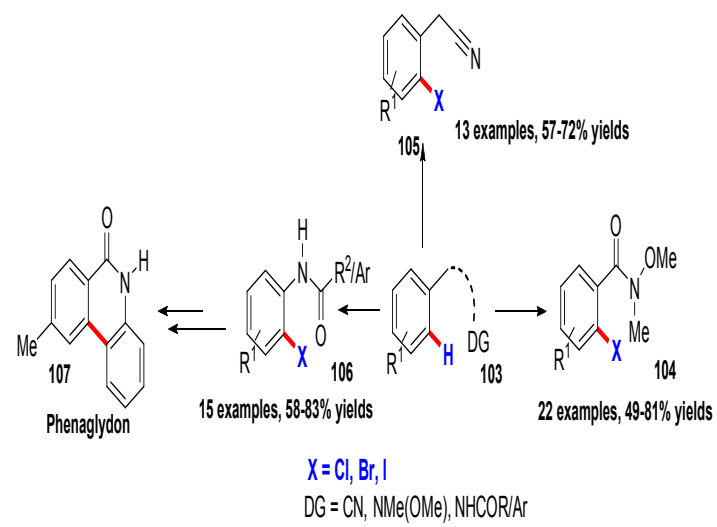

Scheme 27. Palladium-Catalyzed Ortho-Selective C-H halogenation of benzyl nitriles, aryl Weinreb amides 
In 2017, the same group ${ }^{41}$ reporteda straight forward route for the $\mathrm{C}-\mathrm{H}$ halogenation process, inclusive iodination, bromination and chlorination of Weinreb amides 108 , promoted by palladium catalyst (Scheme 28). The successful of this reaction depended on a combination of $\mathrm{Pd}(\mathrm{OAc})_{2}$ and $\mathrm{Cu}(\mathrm{OTf})_{2}$ with $\mathrm{N}$-halosuccinimide109 (NXS; $\mathrm{X}=\mathrm{I}, \mathrm{Br}$ or $\mathrm{Cl}$ ) as the halogen source. The reaction is evaluated by its broadaromatic substrates range, bearing electron-withdrawingand -donatinggroupsexclude the nitro groups, which turn off the reaction fromeach of the ortho or para position.

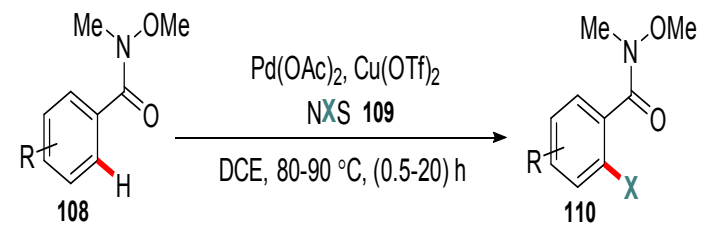<smiles>[X]c1cc(F)ccc1C(=O)N(C)OC</smiles>

Scheme 28. Ortho C-H halogenation of aromatic Weinreb amides

Next, Wei and co-workers ${ }^{42}$ reported the functional usage of Grignard reagents stimulated the unusual decarboxamidation of $\alpha$-arylsulfonyl Weinreb Amides (Scheme 29). The mechanistic studies scope displayed that $\alpha$-sulfo group as electron-withdrawing at the $\alpha$-position of Weinreb amides111, led to easy functionalize of quaternary carbon and $\alpha$-quaternary carbon was the crucial component for providing sulfone products 113 in moderate to good yields (41-86\%). Furthermore, employing excess of Grignard reagent, confirmed the dynamic synthesis of secondary alkyl arylsulfones via $\mathrm{C}-\mathrm{C}$ bond cleavage reaction pathway.

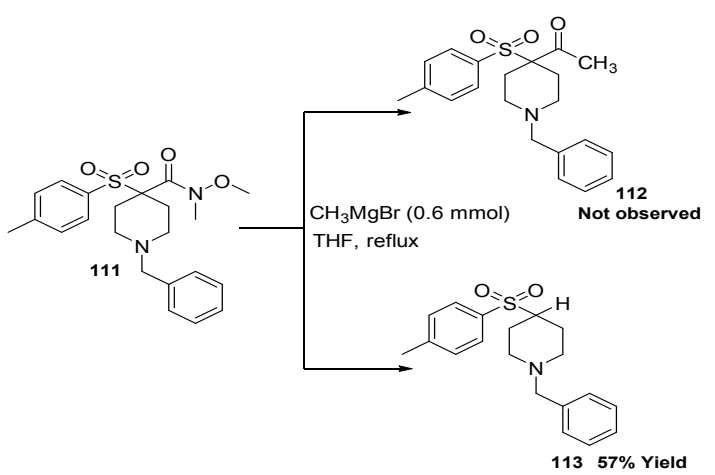

Scheme 29. Unexpected decarboxamidation reaction of the Weinreb amides
In 2018, Joseph and co-workers ${ }^{43}$ reported the first novelroute to the synthesisof several symmetrical and dissymmetrical 2,5cis-disubstituted pyrrolidines by employ the dual reactivity of Weinreb amide species (Scheme 30 ). The protocol here focused on the cleavage reaction of $\mathrm{N}$-alkoxy- $\mathrm{N}$-methylamidefor desymmetrizing a mesobis-Weinreb amide115 through possible metaltemplated arrangement of the two far and quite soft $\mathrm{N}$-methoxy amide functions. On the other hand, the functionalization sequence of 116 with methylamine andbenzylamne117 awarded a straight entry to pyrrolidine products 118 . This method integrated a successive microwave-encouraged tandem double CM/RCDAMfor the preparation of a Weinreb-based pyrrolidine stage to a variety-oriented late-stage functionalization. The authors demonstrated that pattern the steadiness of steric onus of reaction partners, basicity of the organometallic moieties and the liganding potentiality with nitrogen atom of the pyrrolidineisheld to be within the main factors in dominating the reaction selectivity.

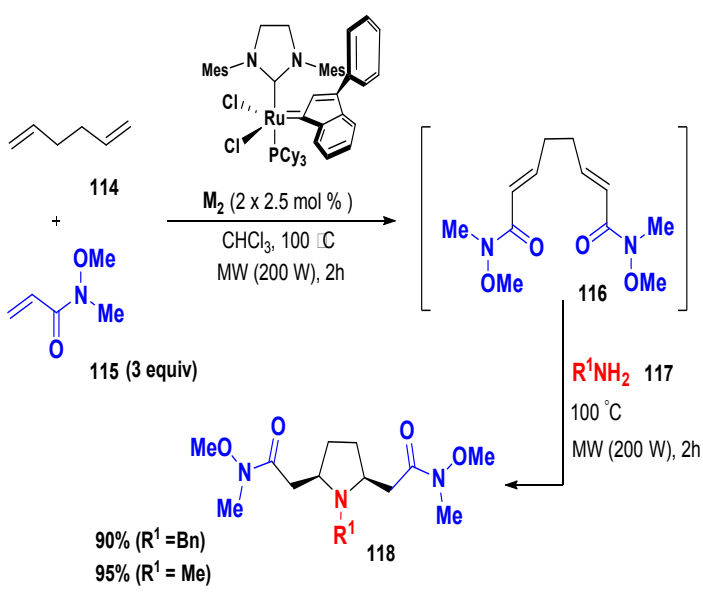

Scheme 30 . Synthesis of 2,5-cis-bis(Weinreb acetamido) pyrrolidines

While, Evano and co-workers ${ }^{44}$ detailed simple and largely usefulroute for transformation of imides into scope of, esters124, carboxylic acids 125, amides126, and Weinreb amides127 in high yieldsunder mild conditions (Scheme 31). Generally, this reaction proceeded through treatinga range of imides 119having different substitution manners with alcohols120, water121, amines122, or N,Odimethylhydroxylamine123, promoted by small amounts of ytterbium(III) triflate as a Lewis acid. The advantages of this reaction are deemed to be inclusive, eco-friendly and mild conditions which simplify the 
one-pot transformation of oxazolidinonederivedimides, versatile intermediates in chemical synthesis.

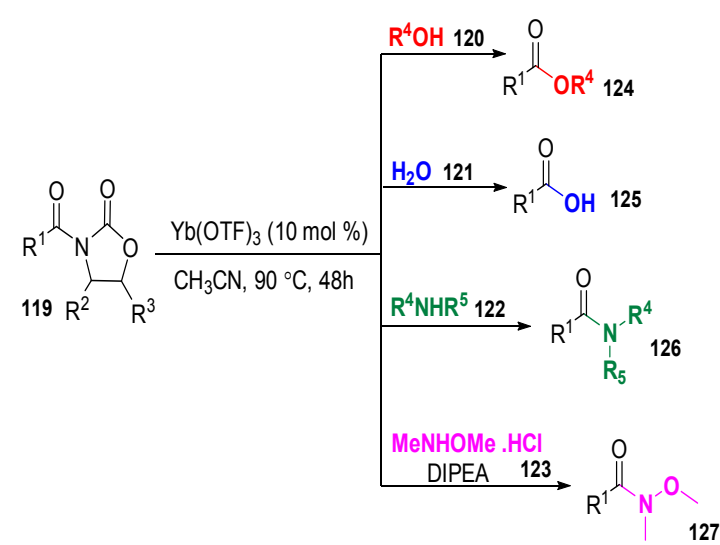

Scheme 31. Ytterbium-Catalyzed esterification, hydrolysis and amidation of imides

Furthermore, Matsunaga group ${ }^{45}$ reportedthe efficient role of $\left(\eta^{5}\right.$-entamethylcyclopentadienyl) cobalt(III) catalyst $\left(\mathrm{Cp}^{*} \mathrm{ColII}\right)$ in the $\mathrm{C}-\mathrm{H}$ bond functionalization of aromatic, heteroaromatic, and $\alpha, \beta$-unsaturated Weinreb amides128 (Scheme 32). Generally, several of $\mathrm{C}-\mathrm{H}$ reactions included allylation, oxidative alkenylation, iodination, and amidation with different reagents such a sallyl carbonate129, ethyl acrylate130, N-iodosuccinimide131, dioxazolones 132 subsequently were catalyzed by $\mathrm{Cp}^{\star} \mathrm{Co}(\mathrm{CO}) \mathrm{I}_{2}$ in the presence of a cationic silver salt and silver acetate to produce respective synthetically valuable building blocks(133-136). Moreover, the mechanistic studies of the $\mathrm{C}-\mathrm{H}$ allylation revealed that the $\mathrm{C}-\mathrm{H}$ activation step was rate determining and practically irreversible.

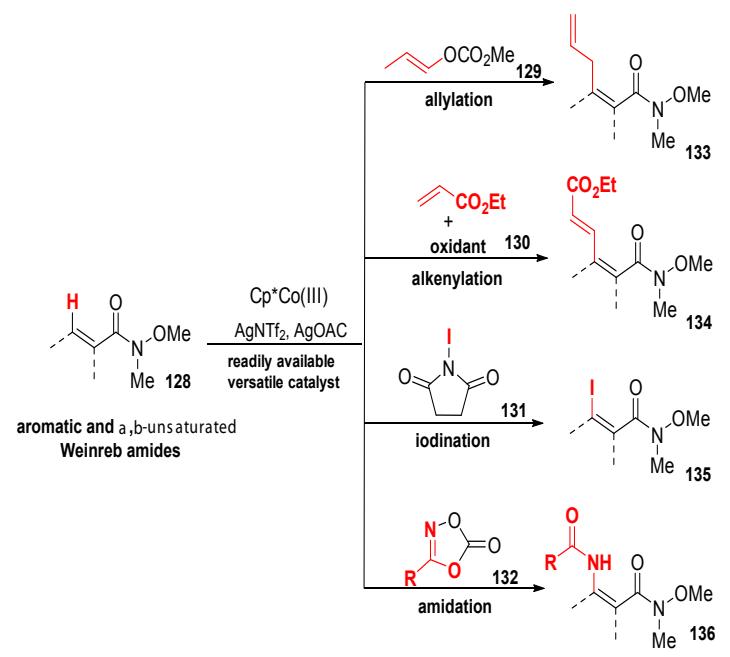

Scheme 32. C-H bond functionalization of Weinreb amide under ( $\eta^{5}$-pentamethylcyclopentadieny) cobalt (III) Catalysis
Later, Yu and co-workers ${ }^{46}$ provided the interest of $\mathrm{Pd}$-catalyzed $\mathrm{C}\left(\mathrm{sp}^{3}\right)-\mathrm{H}$ arylation protocol, which facilitated by Weinreb amide137 as a directing group (Scheme 33). The author's detailed that containment of 3-pyridinesulfonic acid was decisive to such reaction. Furthermore, the computational studies at the DFT level disclosed the importance role of 3-pyridinesulfonic acid for stabilization the cationic palladium catalyst intermediates and accelerate the dissociation of acetate ligands, which led directly cleavage of $\mathrm{C}\left(\mathrm{sp}^{3}\right)-\mathrm{H}$ bond of Weinreb Amides.

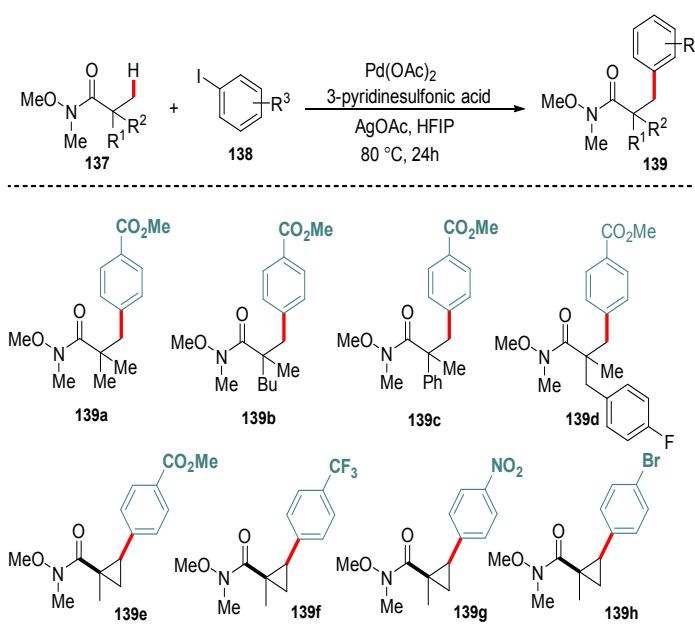

Scheme 33. Pd-catalyzed $\mathrm{C}\left(\mathrm{sp}^{3}\right)-\mathrm{H}$ arylation protocol enabled by Weinreb amide directing group

Most recently, Erbing and co-workers ${ }^{47}$ expanded an Ir(III)-catalyzed C-H ortho-iodination of diverse Weinreb Amides(Scheme 34). The reaction scope included treatment Weinreb Amide substrates 134with N-iodo-succinimide (NIS) 135 as a source of halogen in presence of $\left[\mathrm{Cp}^{*} \operatorname{Ir}\left(\mathrm{H}_{2} \mathrm{O}\right)_{3}\right]\left[\mathrm{SO}_{4}\right]$ as the catalyst and trifluoroacetic acid. It is worth that Weinreb amides gave only mono-iodinated products 136 in high yield (69-92\%), whilst the substratedomain inclusive a wide range of functional groups, substituent's at ortho position to the directing groupat the beginning limited reactivity, perchance by steric hindrance effect.
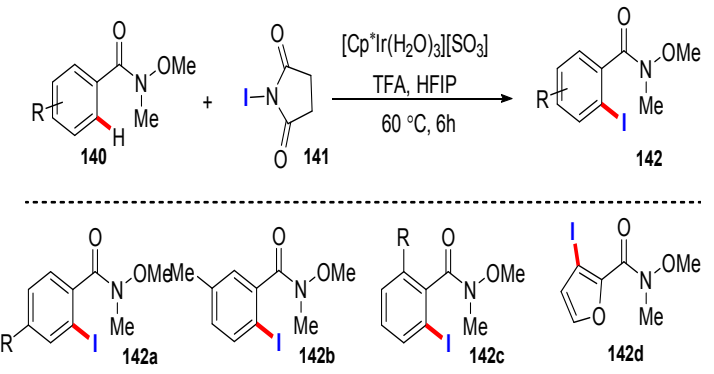

Scheme 34. Ir-catalyzed C-H iodination of Weinreb amides 


\section{CONCLUSION}

More recently, diverse studies have detailed the use of Weinreb amide constructions as delightful substrates in organic synthesis reactions. In this review, we highlighted this part of the literature, containing unusual development synthesis of Weinreb amides and their applications with clarify protocol examples of these processes. Furthermore, this paper contains the ultimate conclusions of the researchers and usefully furnishes reaction information for the most important reaction and many references to the native literature.

\section{ACKNOWLEGEMENT}

We acknowledge the University of Zakho, Faculty of Science, and Department of Chemistry for providing all the facilities.

\section{Conflicts of Interest}

The authors declare no conflict of interest.

\section{REFERENCES}

1. (a) Overhand, M.; Hecht, S. M. A concise synthesis of the anti-fungal agent (+)-preussin. J. Org. Chem., 1994, 59, 4721-4722; (b) Kuethe, J. T.; Comins, D. L., Addition of metalloenolates to chiral 1-acylpyridinium salts: Total synthesis of (+)-cannabisativine. Org. lett., 2000, 2, 855-857; (c) Davis, F. A.; Chao, B., Alkaloid Synthesis Using Chiral $\delta$-Amino $\beta$-Ketoesters: A Stereoselective Synthesis of (-)-Lasubine II. Org.lett., 2000, 2, 2623-2625; (d) Smith, A. B.; Beauchamp, T. J.; LaMarche, M. J.; Kaufman, M. D.; Qu, Y.; Arimoto, H.; Jones, D. R.; Kobayashi, K., Evolution of a gram-scale synthesis of (+)-discodermolide. J. Am. Chem. Soc., 2000, 122, 8654-8664; (e) Crimmins, M. T.; Stanton, M. G.; Allwein, S. P., Asymmetric Total Synthesis of (-)-Laulimalide: Exploiting the Asymmetric Glycolate Alkylation Reaction. J. Am. Chem. Soc., 2002, 124, 5958-5959; (f) Vosburg, D. A.; Vanderwal, C. D.; Sorensen, E. J., A synthesis of (+)-FR182877, featuring tandem transannular Diels-Alder reactions inspired by a postulated biogenesis. J. Am. Chem. Soc., 2002, 124, 4552-4553; (g) Cheung, A. K.; Snapper, M. L., Total Syntheses of (+)-and (-)-Cacospongionolide B: New Insight into Structural Requirements for Phospholipase A2 Inhibition. J. Am. Chem. Soc., 2002, 124, 11584-11585; (h) Mohammed, S., Synthesis of some Substituted-1,3,4-Oxadiazoles, Thiadiazoles and 1,2,4-Triazoles. J. Edu. Sci., 2009, 22, 29: (i) Evans, D.; Trotter, B., Tetrahedron1999, 55, 8671. Evans, DA; Coleman, PJ; Dias, LC. Angew. Chem., Int. Ed. Engl., 1997, 36, 2738; (j) He, W.; Huang, J.; Sun, X.; Frontier, A. J., Total synthesis of
( \pm )-merrilactone A. J. Am. Chem. Soc., 2008 , 130, 300-308; (k) Custar, D. W.; Zabawa, T. P.; Scheidt, K. A., Total synthesis and structural revision of the marine macrolide neopeltolide. J. Am. Chem. Soc., 2008, 130, 804-805.

2. (a)Nahm, S.; Weinreb, S. M., N-Methoxy$\mathrm{N}$-methylamides as effective acylating agents. Tetrahedron Letters., 1981, 22, 3815-3818; (b) Khlestkin, V. K.; Mazhukin, D. G., Recent advances in the application of N,O-dialkylhydroxylamines in organic chemistry. Current Organic Chemistry., 2003, 7, 967-993; (c)Khalid, M.; Shireen, M., Recent Advances in the Multicomponent Synthesis of Pyrano [2, 3-c] pyrazole derivatives. Res. J. Chem. Environ., 2019, 23(10), 139-156; (e) Mohammed, S.Dawood,A. Mahmmoud, M. Synthesis, Identification and Biological Activity of some Schiff bases derived from 1,5diamino naphthalene substrate Res. J. Chem. Environ., 2019, 23(9), 108-112; (d) Khalid, M.; Mohammed, S., Recent Halocyclization Reactions of Alkenes-A Review. Indian J. Hetero. Chem., 2018, 28, 507-527 (e) Maher, K.; Mohammed, S., Recent Trifluoromethylation Reactions. A Mini Review Paper. Orient. J. Chem., 2018, 34, 2708; (f) Maher, K.; Mohammed, S., Crown Ether Schiff bases and Their Complexes: Recent Advances Review. Orient. J. Chem., 2018, 34, 1701-1718.

3. (a) Balasubramaniam, S.; Aidhen, I. S., The growing synthetic utility of the Weinreb amide. Synthesis., 2008, 2008, 37073738; (b) Khlestkin, V. K.; Mazhukin, D. G., Recent advances in the application of $\mathrm{N}$, O-dialkylhydroxylamines in organic chemistry. Current Organic Chemistry., 2003, 7, 967-993; 
(c) Sibi, M. P., Chemistry of N-methoxy-Nmethylamides. Applications in synthesis. A review. Organic preparations and procedures international., 1993, 25, 15-40; (d) Beniazza, R.; Liautard, V.; Poittevin, C.; Ovadia, B.; Mohammed, S.; Robert, F.; Landais, Y. Free-Radical Carbo-Alkenylation of Olefins: Scope, Limitations and Mechanistic Insights. Chem-A. Eur. J., 2017, 23, 2439-2447; (e) Mohammed, S. R. Development of new radical processes: approaches toward the synthesis of Eucophylline. Ph.D. Thesis, Bordeaux1 University, Bordeux, France, 2014; (f) Khalid, M.; Mohammed, S. Recent Free-Radical Reactions, Asian J. Chem., 2019, 31(1), 25-40; (g) Mohammed, S.; Khalid, M., High Efficient of the Intermolecular Radical Reactions through three-Component Carbo-Oximation Process use a new ready available Sulfonyloxime. Orient. J. Chem., 2015, 31, 1319-1326; (h) Mohammed, S.; Khalid, M., Novel Free-Radical Mediated Carboalkenylation of Olefins Processes Starting from Ready Available Benzylketone and Weinreb Amide Xanthate as a Electrophilic Radical Precursors and E-Sulfone Acceptor. J. Indian Chem. Soc., 2015, 92, 1569-1578.

4. (a) Ruiz, J.; Sotomayor, N.; Lete, E., Parham-type cycliacylation with Weinreb amides. Application to the synthesis of fused indolizinone systems. Org.lett., 2003, 5, 1115-1117; (b) Niu, T.; Zhang, W.; Huang, D.; Xu, C.; Wang, H.; Hu, Y., A powerful reagent for synthesis of Weinreb amides directly from carboxylic acids. Org.lett., 2009, 11, 4474-4477; (c) Taillier, C.; Bellosta, V.; Meyer, C.; Cossy, J., Synthesis of $\omega$-Hydroxy Ketones from $\omega$-Benzyloxy Weinreb Amides by Using a Chemoselective Nucleophilic Addition/ Birch Reduction Process. Org.lett., 2004, 6, 2145-2147; (d) Mohammed, S.; Maher, K. A., Synthesis and Spectral Characterization of 1, 5-Naphthyridine Derivatives through CrossCoupling Suzuki Reaction. Indian J. Hetero. Chem., 2019, 29, 199-203; (e) Mohammed, S.; Khalid, M., A facile Synthesis of Quinazolinone Derivatives Through VilismeierIntermediate. Indian J. Hetero. Chem., 2017, 27(3), 8387; (f) Mohammed, S.,A Novel Synthetic Route of Fused Tricyclic Framework Quinoline Derivatives from Readily Available Aliphatic
Amino Carboxylic Acid Substrates, Orient. J. Chem., 2019, 35(2), 611-617; (g) Mohammed, S., Maher, K.,Dawood, A.A Flexible Protocol for the Preparation of Quinoline Derivatives through Mitsunobu Reaction and Aza-Wittig Intermediate, Indian J. Hetero. Chem., 2017, 27(4), 457-462.

5. (a) Conrad, R. M.; Grogan, M. J.; Bertozzi, C. R., Stereoselective synthesis of myo-inositol via ring-closing metathesis: A building block for glycosylphosphatidylinositol (GPI) anchors synthesis. Org.let., 2002, 4, 1359-1361.

6. Singh, J.; Satyamurthi, N.; Aidhen, I. S., The Growing Synthetic Utility of Weinreb' s Amide. Journal fürpraktische Chemie., 2000, 342 , 340-347.

7. (a) Murphy, J. A.; Commeureuc, A. G.; Snaddon, T. N.; McGuire, T. M.; Khan, T. A.; Hisler, K.; Dewis, M. L.; Carling, $\mathrm{R}$., Direct conversion of $\mathrm{N}$-methoxy-Nmethylamides (Weinreb amides) to ketones via a nonclassical Wittig reaction. Org.lett., 2005, 7,1427-1429; (b) Hisler, K.; Tripoli, R.; Murphy, J. A., Reactions of Weinreb amides: formation of aldehydes by Wittig reactions. Tetrahedron Lett., 2006, 47, 6293-6295.

8. (a) Braun, M.; Waldmüller, D., Simple Three-Step Synthesis of (R)-and (S)-4Amino-3-hydroxybutanoic Acid (GABOB) by StereoselectiveAldol Addition. Synthesis. 1989, 1989, 856-858; (b) Sawamura, M.; Nakayama, Y.; Kato, T.; Ito, Y., Gold (I)-Catalyzed Asymmetric Aldol Reaction of N-Methoxy-Nmethyl-. alpha.-isocyanoacetamide -alpha.IsocyanoWeinreb Amide). An Efficient Synthesis of Optically Active. beta.-Hydroxy. alpha.-Amino Aldehydes and Ketones. J. Org. Chem., 1995, 60, 1727-1732; (c) Gibson, C L.; Handa, S., An expedient synthesis of (R)(+)-umbelactone. TetrahedronAsym., 1996, 7, 1281-1284; (d) Niu, T.; Zhang, W.; Huang, D.; Xu, C.; Wang, H.; Hu, Y., A powerful reagent for synthesis of Weinreb amides directly from carboxylic acids. Organic letters., 2009, 11, 4474-4477; (e) Moyer, M. P.; Shiurba, J. F.; Rapoport, H., Metal-halogen exchange of bromoindoles. A route to substituted indoles. J. Org. Chem., 1986, 51, 5106-5110; (f) Goel, O.; Krolls, U.; Stier, M.; Kesten, S., N-tertbutoxycarbonyl-L-leucinal. Org. Synth., 1988, 67, 69-69; (g) Thesis, P. D.; Heathcock, C. H., 
Improved procedure for preparation of optically active 3-hydroxyglutarate monoesters and 3-hydroxy-5-oxoalkanoic acids. J. Org. Chem., 1988, 53, 2374-2378; (h) Jones, T. K.; Mills, S. G.; Reamer, R. A.; Askin, D.; Desmond, R.; Volante, R.; Shinkai, I., Total synthesis of immunosuppressant (-)-FK-506. J. Am Chem. Soc., 1989, 111, 1157-1159 (i) ALNiami Khalid M. Daoud, M., Mohammed, S., Najham M., Synthesis of Subsituted-1,3,4 Oxadiazoles-1,3,4-Thiadiazolesand1,2,4Triazolesfrom-2-(2,3-dimethy Iphenyl amino) benzoic acid. J. Edu. Sci., 2009, 22, 1-10; (J) Nitz, T. J.; Volkots, D. L.; Aldous, D. J.; Oglesby, R. C., Regiospecific synthesis of 3-substituted 5-alkylisoxazoles from oximedianions and $\mathrm{N}$-methoxy-N-methylalkylamides. J. Org. Chem., 1994, 59, 5828-5832.

9. Goel, O.; Krolls, U., synthesis of $\mathrm{n}$, o-dimethylhydroxylamine hydrochloride. Organic preparations and procedures international., 1987, 19, 75-78.

10. Dineen, T. A.; Zajac, M. A.; Myers, A. G., Efficient transamidation of primary carboxamides by in situ activation with $\mathrm{N}$, $\mathrm{N}$-dialkylformamide dimethyl acetals. J. Am. Chem. Soc., 2006, 128, 16406-16409.

11. (a) Basha, A, M, and Steven M. Weinreb. "A mild, general method for conversion of esters to amides." Tetrahedron letters., 1977, 18(48): 4171-4172. (b) Sha, C.-K.; Huang, S.-J.; Zhan, Z.-P., Anionic cyclization approachs toward perhydrobenzofuranone: stereocontrolled synthesis of the hexahydrobenzofuran subunit of avermectin. J. Org. Chem., 2002, 67, 831836.(c) Colobert, F.; Mazery, R. D.; Solladié, G.; Carreno, M. C., First enantioselective total synthesis of (-)-centrolobine. Organic letters., 2002, 4, 1723-1725. (d) Jaipuri, F. A.; Jofre, M. F.; Schwarz, K. A.; Pohl, N. L., Microwave-assisted cleavage of Weinreb amide for carboxylate protection in the synthesis of a (R)-3-hydroxyalkanoic acid. Tetrahedron lett., 2004, 45, 4149-4152; (e) Hassan, H.; Mohammed, S.; Robert, F. d. r.; Landais, Y., Total Synthesis of $( \pm)$-Eucophylline. A Free-Radical Approach to the Synthesis of the Azabicyclo [3.3. 1] nonane Skeleton. Org. lett. 2015, 17, 45184521; (f) Mohammed, S., Maher, K., A Facile Entry to Fused Dipyrimidine: Preparation of Imidazo[1,2-a:3,4-a'] Dipyrimidine-4,9(3H)-
Dione and Pyrimido[1',2':4,5] Pyrazino[1,2-a] Pyrimidine-4,10(3H,6H)-Dione Derivatives. Indian J. Hetero. Chem., 2017, 27(3), 1-6; (g) Mohammed, S.; KHALID, M., A Facile Protocol for the Construction of Tricyclic Framework Tetrahydrobenzo-4-nitrobenzenesulfonate, 4-methylbenzenesulfonate and $[1,8]$ naphthyridine Substituents from Methyl $\delta$-Lactam. Orient. J. Chem., 2015, 31(4), 2137-2146; (h) Daoud, K. M.; Mohammed, S. R.; Saeed, Z. F., Synthesis and Antibacterial Activity of 2-Cinnamyl-5-Substituted-1, 3, 4-Oxadiazole, 1, 3, 4-Thiadiazoles and 5-Cinnamyl-3-Substituted-1, 2, 4-Triazoles. Iraqi Nat. J. Chem., 2007, 102-110.

12. Shimizu, T.; Osako, K.; Nakata, T.-i., Efficient method for preparation of N-methoxy-Nmethyl amides by reaction of lactones or esters with $\mathrm{Me}_{2} \mathrm{AlCl}_{3} \mathrm{MeONHMe} \bullet \mathrm{HCl}$. Tetrahedron Lett., 1997, 38, 2685-2688.

13. Jacobi, P. A.; Kaczmarek, C. S.; Udodong, U. E., Bisheteroannulation. 8. Total synthesis of (士)-paniculide-A. Tetrahedron Lett., 1984, 25, 4859-4862.

14. Kim, J.-G.; Jang, D. O., A convenient one-pot method for the synthesis of N-methoxy-Nmethyl amides from carboxylic acids. Bull Korean Chem.Soc., 2010, 31, 171-173.

15. Davis, F. A.; Theddu, N., Asymmetric Synthesis of Cyclic cis- $\beta$-Amino Acid Derivatives Using Sulfinimines and Prochiral Weinreb Amide Enolates. J. Org. Chem., 2010, 75, 3814-3820.

16. Kommidi, H.; Balasubramaniam, S.; Aidhen, I. S., Weinreb amide based synthetic equivalents for convenient access to 4-aryl-1, 2, 3, 4-tetrahydroisoquinolines. Tetrahedron., 2010, 66, 3723-3729.

17. Krishnamoorthy, R.; Lam, S. Q.; Manley, C. M.; Herr, R. J., Palladium-catalyzed preparation of Weinreb amides from boronic acids and $\mathrm{N}$-methyl-N-methoxycarbamoyl chloride. J. Org. Chem., 2010, 75, 1251-1258.

18. Kumar, A.; Akula, H.K.; Lakshman, M.K., Simple Synthesis of Amides and Weinreb Amides Using $\mathrm{PPh}^{3}$ or Polymer-Supported $\mathrm{PPh}^{3}$ and lodine. Euro-J. org. chem., 2010, 2709-2715.

19. Wieckowska, A.; Fransson, R.; Odell, L. R.; Larhed, M., Microwave-assisted synthesis of weinreb and MAP aryl amides viaPd-catalyzed heck aminocarbonylation using $\mathrm{Mo}(\mathrm{CO})_{6}$ or W (CO). . J. Org. Chem., 2011, 76, 978-981. 
20. Balasubramaniam, S.; Kommidi, H.; Aidhen, I. S.,Weinreb amide based building blocks for convenient access to 1,1-diarylethenes and isocombretastatin analogues. Tetrahedron Lett., 2011, 52, 2683-2686.

21. Greger, J. G.;Yoon-Miller, S. J.; Bechtold, N. R.; Flewelling, S. A.; MacDonald, J. P.; Downey, C. R.; Cohen, E. A.; Pelkey, E. T., Synthesis of unsymmetrical 3, 4-diaryl-3-pyrrolin-2ones utilizing pyrroleweinreb amides. J. Org. Chem., 2011, 76, 8203-8214.

22. Tyrrell, E.; Brawn, P.; Carew, M.; Greenwood, I., An expedient conversion of $\alpha$-amino acids into Weinreb amides using COMU $®$ as a coupling agent. Tetrahedron lett., 2011, 52, 369-372.

23. MengMeg, Z.; WanFang, L.; Xin, M.; WeiZheng, F.;XiaoMing, T.; XiaoMing, L.; XiaoMin, X.; ZhaoGuo, Z.Ru-catalyzed highly enantioselective hydrogenation of $\alpha$-keto Weinreb amides.Science china chemistry., 2013, 56(3), 342-348.

24. Bommegowda, Y. K.; Lingaraju, G. S.; Thamas, S.; Kumar, K. S. V.; Kumara, C. S. P.; Rangappa, K. S.; Sadashiva, M. P., Weinreb amide as an efficient reagent in the one pot synthesis of benzimidazoles and benzothiazoles. Tetrahedron Lett., 2013, 54, 2693-2695.

25. Pace, V.; Castoldi, L.; Alcántara, A. R.; Holzer, W., Highly efficient and environmentally benign preparation of Weinreb amides in the biphasic system 2-MeTHF/water. RSC Advances., 2013, 3, 10158-10162.

26. Davies, S. G.; Fletcher, A. M.; Thomson, J. E., Direct asymmetric syntheses of chiral aldehydes and ketones via $\mathrm{N}$-acyl chiral auxiliary derivatives including chiral Weinreb amide equivalents. Chemical Communications., 2013, 49, 8586-8598.

27. Sharnabai, K.; Nagendra, G.; Vishwanatha, T.; Sureshbabu, V. V., Efficient synthesis of $\mathrm{N}$-protected amino/peptide Weinreb amides from T3P and DBU. Tetrahedron lett., 2013, 54, 478-482.

28. Gadge, S.T.; Bhanage, B. M., Pd(OAc)2/DABCO as an efficient and phosphine-free catalytic system for the synthesis of single and double Weinreb amides by the aminocarbonylation of aryl iodides. Organic \& biomolecular chemistry., 2014, 12, 5727-5732.

29. Silwal, S.; Rahaim, R. J., Regioselective synthesis of enonesvia a titanium-promoted coupling of unsymmetrical alkynes with weinreb amides. J. org. chem., 2014, 79, 8469-8476.

30. Dang, T. T.; Chen, A.; Seayad, A. M., An Efficient synthesis of Weinreb amides and ketones via palladium nanoparticles on ZIF-8 catalysedcarbonylative coupling. RSC Advances., 2014, 4, 30019-30027.

31. Jackson, J. E.; O’Brien, B. N.; Kedzior, S. K.; Fryz, G. R.; Jalloh, F. S.; Banisafar, A.; Caldwell, M. A.; Braun, M. B.; Dunyak, B. M.; Dye, J. L., Reductive $\mathrm{N}-\mathrm{O}$ cleavage of Weinreb amides by sodium in alumina and silica gels: synthetic and mechanistic studies. Tetrahedron lett., 2015, 56, 6227-6230.

32. Wang, Y.; Zhou, K.; Lan, Q.; Wang, X.-S., Pd (ii)-catalyzed $\mathrm{C}-\mathrm{H}$ arylation of aryl and benzyl Weinreb amides. Organic \&biomolecular chemistry., 2015, 13, 353-356.

33. Shirai, T.; Yamamoto, Y., Cationic Iridium/S-Me-BIPAM-Catalyzed Direct Asymmetric Intermolecular Hydroarylation of Bicycloalkenes. Angewandte Chemie International Edition., 2015, 54, 9894-9897.

34. Das, R.; Kapur, M., Fujiwara-Moritani Reaction of Weinreb Amides using a RutheniumCatalyzed C-H Functionalization Reaction. Chemistry-An Asian Journal., 2015, 10 , 1505-1512.

35. Das, R.; Kapur, M., Product Control using Substrate Design: Ruthenium-Catalysed Oxidative $\mathrm{C}-\mathrm{H}$ Olefinations of Cyclic Weinreb Amides. Chem-A Euro. J., 2016, 22, 16986-16990.

36. Wang, Y.-N.; Sun, G.-X.; Qi, G., $\beta$-Amino functionalization of cinnamic Weinreb amides in ionic liquid. Beilstein journal of organic chemistry., 2016, 12, 2372-2377.

37. Houghton, M. J.; Collum, D. B., Lithium Enolates Derived from Weinreb Amides: Insights into Five-Membered Chelate Rings. J.orga.Chem., 2016, 81, 11057-11064.

38. (a) Fabry, D. C.;Rueping, M., Merging visible light photoredox catalysis with metal catalyzed $\mathrm{C}-\mathrm{H}$ activations: on the role of oxygen and superoxide ions as oxidants. Accounts of chemical research., 2016, 49, 1969-1979; (b) Fabry, D. C.; Zoller, J.; Raja, S.; Rueping, M., Combining Rhodium and Photoredox Catalysis for C- H Functionalizations of Arenes: Oxidative Heck Reactions with Visible Light. AngewandteChemie International Edition., 2014, 53, 10228-10231. 
39. Castoldi, L.; Holzer, W.; Langer, T.; Pace, V., Evidence and isolation of tetrahedral intermediates formed upon the addition of lithium carbenoids to Weinreb amides and $\mathrm{N}$-acylpyrroles. Chemical Communications., 2017, 53, 9498-9501.

40. Das, R.;Kapur, M., Palladium-Catalyzed, ortho-Selective C-H Halogenation of Benzyl Nitriles, Aryl Weinreb Amides, and Anilides. J. org. chem., 2017, 82, 1114-1126.

41. Das, R.; Kapur, M. Palladium-Catalyzed, ortho-Selective C-H Halogenation of Benzyl Nitriles, Aryl Weinreb Amides, and Anilides. J. Org. Chem., 2017, 82, 1114-1126.

42. Liu, W.; Li, H.; Qin, H.; Zhao, W.; Zhou, C.; Jiang, S.; Yang, C., Unexpected decarboxamidation of $\alpha$-arylsulfonylWeinreb amides by Grignard reagents: Synthesis of $\alpha$-disubstitutedarylsulfones. Chemical Research in Chinese Universities., 2017, 33, 213-220.

43. Boufroura, H.; Sevaille, L.; Gigant, N.; Drège, E.; Joseph, D., The dual reactivity of Weinreb amides applied to the late-stage divergent functionalisation of mesopyrrolidines. New Journal of Chemistry., 2018, 42, 12403-12411.

44. Guissart, C.I.;Barros, A.; Rosa Barata, L.; Evano, G., Broadly Applicable Ytterbium-Catalyzed Esterification, Hydrolysis, and Amidation of Imides. Org.lett., 2018, 20, 5098-5102.

45. Kawai, K.; Bunno, Y.; Yoshino, T.; Matsunaga, S., Weinreb Amide Directed Versatile C- $\mathrm{H}$ Bond Functionalization under ( $\eta^{5}$ Pentamethylcyclopentadienyl) cobalt (III) Catalysis. Chem-A Eur. J., 2018, 24, 1023110237.

46. Park, H.; Chekshin, N.; Shen, P.-X.; Yu, J.-Q., Ligand-Enabled, Palladium-Catalyzed $\beta-C$ $\left(\mathrm{sp}^{3}\right)-\mathrm{H}$ Arylation of Weinreb Amides. ACS catalysis., 2018, 8, 9292-9297.

47. Erbing, E. Development of New Efficient Iridium-Catalyzed Methods for the Construction of Carbon-Heteroatom Bonds. Ph.D. Thesis, Stockholm University, Stockholm, Sweden., 2018. 